\title{
Abundância e sazonalidade do ácaro-rajado em cultivares de gérbera
}

\author{
Abundance and seasonality of two-spotted spider mite on gerbera cultivars
}

\author{
Manuela Sulzbach ${ }^{\mathrm{I}}$ Ricardo Ott ${ }^{\mathrm{II}}$ Gilmar Schafer ${ }^{\mathrm{I}}$ Ana Paula Ott ${ }^{\mathrm{I}}$
}

RESUMO

\begin{abstract}
Neste estudo foi avaliada a abundância $e$ a sazonalidade de Tetranychus urticae Koch, 1836 em três cultivares de Gerbera jamesonii Adlam., em cultivo comercial no sul do Brasil. Para avaliação destes parâmetros foram realizadas amostragens de abril de 2011 a fevereiro de 2012. Os ácaros foram obtidos a partir de flores e folhas retiradas de cada uma das cultivares. No total foram contabilizados 10.640 ácaros e de acordo com os testes, a cultivar "Pink Snow" apresentou maior abundância significativa. A análise estatística não evidenciou diferença entre o número de ácaros presentes nas folhas e flores. Em todas as variedades o maior número de T. urticae foi registrado na primavera.
\end{abstract}

Palavras-chave: Tetranychus urticae, Gerbera jamesonii, flutuação populacional.

\section{ABSTRACT}

In this study it was evaluated the abundance and seasonality of Tetranychus urticae Koch, 1836 in three varieties of Gerbera jamesonii Adlam. in a commercial cultivation at the south of Brazil. For the evaluation of these parameters samplings were accomplished from April 2011 to February 2012. The mites were obtained from flowers and leaves removed from each one of the studied varieties. A total of 10,640 mites were counted, and in agreement with the tests, there were a significant larger number of mites in the "Pink Snow" variety. The statistical analysis didn't evidence conclusive differences in the mite numbers between leaves and flowers. In all three varieties the largest number of $\boldsymbol{T}$. urticae was registered in the spring.

Key words: Tetranychus urticae, Gerbera jamesonii, population fluctuation.

\section{INTRODUÇÃO}

A gérbera (Gerbera jamesonii Adlam.) é tradicionalmente cultivada como flor de corte estando entre as plantas ornamentais de maior importância comercial no Brasil, mercado este que movimenta anualmente US\$ 1,3 bilhão (BUAINAIN \& BATALHA, 2007, SEBRAE, 2011). No Rio Grande do Sul, a gérbera é a terceira flor de corte mais vendida, sendo superada apenas pela rosa e pelo crisântemo (SEBRAE, 2003). O cultivo de gérberas em estufa proporciona maior proteção às flores em relação a fatores climáticos prejudiciais como vento e chuva (FISCHER, 2008). No entanto, as condições ambientais no interior da estufa podem proporcionar temperatura e umidade relativa do ar ótimas para o rápido crescimento de pragas, em especial os ácaros (ZHANG, 2003).

No Brasil, levantamentos da acarofauna em plantas ornamentais têm constatado Tetranychidae como a família de ácaros fitófagos mais abundante (FERES et al., 2009, SANTOS et al., 2010). Entre as espécies de Tetranychidae relacionadas como pragas comuns em cultivo protegido, destaca-se o ácaro-rajado Tetranychus urticae Koch que através de sua alimentação, provoca em gérberas, pontuações cloróticas na face adaxial das folhas, que evoluem para clorose intensa, bronzeamento e necrose dos tecidos afetados, ocasionando perda de área fotossintética e redução no tamanho e na produtividade da planta,

'Programa de Pós-graduação em Fitotecnia, Universidade Federal do Rio Grande do Sul (UFRGS), 90540-000, Porto Alegre, RS, Brasil. E-mail: ana.ott@ufrgs.br. *Autor para correspondência.

IMuseu de Ciências Naturais, Fundação Zoobotânica do Rio Grande do Sul, Porto Alegre, RS, Brasil. Recebido 07.11.13 Aprovado 13.08.14 Devolvido pelo autor 28.11.14 CR-2013-1494.R3 
afetando assim o tamanho das inflorescências. Ainda se podem identificar distorções dos botões em formação e flores deformadas, em grandes infestações a planta pode ser coberta por teia e morrer prematuramente (GALLO et al., 2002, ZHANG, 2003). Estudos sobre a abundância e a sazonalidade de $\boldsymbol{T}$. urticae em $\boldsymbol{G}$. jamesonii não são conhecidos. Todavia existem alguns trabalhos sobre interações entre estas duas espécies, que tratam sobre a biologia, controle químico, influência de características morfológicas da planta, como tricomas e interações tritróficas entre estas espécies e ácaros predadores (DICKE, 1988a, KRIPS et al., 1998, 2001, SILVA et al., 2009, SCHWERTNER, 2012). Considerando o fato da valorização da produção de flores de corte estar diretamente associada à qualidade estética destas, o ácaro-rajado representa um fator limitante em sua produção. Em razão da inexistência de dados sobre a dinâmica populacional do ácaro-rajado em variedades de gérbera, este estudo teve como objetivo o conhecimento da abundância e da sazonalidade de T. urticae nas cultivares 'Pink Snow', 'Essandre' e 'Sarinah' em cultivo protegido.

\section{MATERIAL E MÉTODOS}

O presente trabalho foi desenvolvido em cultivo protegido de Gerbera jamesonii Adlam. na Floricultura Florist Ltda., município de Dois Irmãos, Rio Grande do Sul, Brasil (29³4'56"S, 51 $\left.{ }^{\circ} 5^{\prime} 40^{\prime \prime} \mathrm{O}\right)$. As coletas foram realizadas de abril de 2011 a fevereiro de 2012 (11 meses de amostragem) sempre no horário entre as $9 \mathrm{~h}$ e $10 \mathrm{~h} 30 \mathrm{~min}$, totalizando oito datas amostrais, duas a cada estação do ano. Para determinar a abundância de $\boldsymbol{T}$. urticae nas diferentes variedades de gérbera, a cada data amostral foram coletadas aleatoriamente 10 flores e 10 folhas de diferentes plantas de cada uma das cultivares de G. jamesonii: "Essandre" (E), "Sarinah" (S) e "Pink Snow" (PS), totalizando 30 flores e 30 folhas por data amostral. A área foliar média para as três cultivares é de $114,52 \mathrm{~cm}^{2}$ e o diâmetro médio das inflorescências é de $9,87 \mathrm{~cm}$ (SENAPATI et al., 2013). Os ácaros foram retirados das amostras e montados em lâminas contendo meio de Hoyer (JEPPSON et al., 1975). A identificação foi realizada através de chaves (VILELA, 1975, BAKER \& TUTLE, 1994, ZHANG, 2003).

Cada uma das variedades de gérberas foi cultivada separadamente em canteiros elevados com $50 \mathrm{~cm} \times 100 \mathrm{~cm} \times 500 \mathrm{~cm}$ (A x L x C), formando blocos únicos em uma estufa agrícola $(5 \mathrm{mx} 53 \mathrm{mx} 54 \mathrm{~m})$, coberta com plástico (PEBD) com filtro UV. O controle da temperatura foi feito com o emprego de malha termo-reflectora e abertura das cortinas, realizadas diariamente para auxiliar na ventilação do ambiente. O manejo fitossanitário da cultura foi preventivo, realizando-se semanalmente a aplicação de agroquímicos com ação fungicida, inseticida, acaricida e acaricida/inseticida em sistema de rotação de ingredientes ativos para evitar a indução de resistência às pragas. Como medida paliativa, foi realizada a lavagem das plantas com ducha de água para eliminação mecânica de ácaros e insetos nos períodos de altas infestações.

A abundância de $\boldsymbol{T}$. urticae foi analisada considerando a localização na planta (flores e folhas) e sazonalidade (estações do ano), com base na média de ácaros presentes em cada ocasião de amostragem. Os dados foram submetidos à análise estatística através do teste $t$ de Student $(\mathrm{t})$, teste de Mann-Whitney (U), ANOVA (F) e Kruskall-Wallis (H), com teste de Tukey a "posteriori", todos a 5\% de probabilidade de erro $(\mathrm{P}<0,005)$ e processados com o programa SigmaStat versão3.5 (JANDEL, 2007).

\section{RESULTADOS E DISCUSSÃO}

No total das amostragens, foram contabilizados 10.640 indivíduos pertencentes à Tetranychus urticae. Destes, 2.138 (20,1\%) em E, $6.210(58,4 \%)$ em PS e $2.292(21,5 \%)$ em S, apresentando diferença significativa entre PS x E e PS x S (ANOVA; $\mathrm{h}=48,851, \mathrm{P}=<0,001)$. As diferenças no número de ácaros registrados apenas entre as flores das diferentes cultivares ou apenas entre folhas das diferentes cultivares, para cada uma das datas de coleta, estão representadas na tabela 1 . De acordo com os resultados, para a maioria das datas de coleta, houve diferença significativa entre o número de ácaros nas diferentes cultivares tanto em flores como em folhas. Não foram constatadas diferenças significativas apenas em Novembro/2011para flores $(\mathrm{H}=4,48, \mathrm{P}=0,107)$ e para as folhas $(\mathrm{H}=2,47$, $\mathrm{P}=0,291)$ e em Fevereiro/2012 para o número de $\boldsymbol{T}$. urticae nas folhas $(\mathrm{H}=2,05, \mathrm{P}=0,148)$. Em 87,5\% das datas amostrais as diferenças entre PS e as outras variedades demonstraram-se significativas tanto para flores como para folhas. Em Janeiro/2012 houve diferença significativa apenas entre PS e S para flores e entre PS e E somente para folhas. Esses resultados sugerem uma clara preferência dos ácaros por PS.

Estudos indicam que características de diferentes genótipos de plantas de importância econômica como o algodoeiro, o morangueiro, o tomateiro e o mamoeiro, podem influenciar no desenvolvimento biológico de $\boldsymbol{T}$. urticae 
Tabela 1 - Número médio de Tetranychus urticae em flores e folhas de três cultivares de Gerbera jamesonii, no período de abril de 2011 a fevereiro de 2012, no município de Dois Irmãos, RS, Brasil.

\begin{tabular}{|c|c|c|c|c|}
\hline Data & Região & 'Essandre' & 'Pink Snow' & 'Sarinah' \\
\hline \multirow[t]{2}{*}{ Abril/2011 } & Flores & $13,9 a$ & $38,6 b$ & $10,7 \mathrm{a}$ \\
\hline & Folhas & $7,6 \mathrm{a}$ & $37,1 \mathrm{~b}$ & $11,8 \mathrm{a}$ \\
\hline \multirow[t]{2}{*}{ Junho/2011 } & Flores & $2,7 \mathrm{a}$ & $45,2 \mathrm{~b}$ & $0,5 \mathrm{a}$ \\
\hline & Folhas & $8,9 \mathrm{a}$ & $50,4 b$ & $11,7 \mathrm{a}$ \\
\hline \multirow[t]{2}{*}{ Julho/2011 } & Flores & $0,2 \mathrm{a}$ & $11,3 b$ & $0,4 \mathrm{a}$ \\
\hline & Folhas & $1,9 \mathrm{a}$ & $23,7 b$ & $3,3 \mathrm{a}$ \\
\hline \multirow[t]{2}{*}{ Setembro/2011 } & Flores & $0,1 \mathrm{a}$ & $9,4 \mathrm{~b}$ & $0,8 \mathrm{ab}$ \\
\hline & Folhas & $0,8 \mathrm{a}$ & $26,1 b$ & $1,7 \mathrm{a}$ \\
\hline \multirow[t]{2}{*}{ Outubro/2011 } & Flores & $3,20 \mathrm{a}$ & $90,0 \mathrm{~b}$ & $22,4 a$ \\
\hline & Folhas & $16,4 a$ & $66,6 b$ & $27,8 \mathrm{a}$ \\
\hline \multirow[t]{2}{*}{ Novembro/2011 } & Flores & $33,4 a$ & $49,8 b$ & $27,7 \mathrm{a}$ \\
\hline & Folhas & $52,3 \mathrm{a}$ & $70,9 b$ & $68,5 \mathrm{a}$ \\
\hline \multirow[t]{2}{*}{ Janeiro/2012 } & Flores & $14,0 \mathrm{ab}$ & $29,0 \mathrm{~b}$ & $2,7 \mathrm{a}$ \\
\hline & Folhas & $14,5 \mathrm{ab}$ & $47,0 \mathrm{~b}$ & $15,4 \mathrm{ab}$ \\
\hline \multirow[t]{2}{*}{ Fevereiro/2012 } & Flores & $0 \mathrm{a}$ & $0,5 b$ & $11,1 \mathrm{a}$ \\
\hline & Folhas & $15,1 \mathrm{a}$ & $20,1 \mathrm{a}$ & $12,7 \mathrm{a}$ \\
\hline
\end{tabular}

Valores nas linhas seguidos pela mesma letra não são significativos de acordo com ANOVA $(\mathrm{P}<0,05)$ e Kruskall-Wallis (Tukey) $(\mathrm{P}<0,05)$.

(LOURENÇÃO et al., 2000, MARUYAMA et al., 2002, ESTEVES FILHO et al., 2010, MORO et al., 2012), evidenciando cultivares mais ou menos atrativas à espécie. Um dos fatores que pode induzir diferenças no desenvolvimento desta espécie ocorre em função da alimentação dos ácaros fitófagos. Esses ácaros induzem a liberação de compostos voláteis produzidos pela planta hospedeira, podendo atrair tanto ácaros fitófagos quanto ácaros predadores (DICKE, 1988a, PALLINI et al., 1997). Segundo diversos autores (DICKE, 1988b, TAKABAYASHI et al., 1991; KIELKIEWICZ \& DICKE, 1992), os voláteis liberados podem variar entre as espécies de plantas e entre as cultivares. No caso da gérbera, é possível que diferentes cultivares de gérberas produzam voláteis distintos a partir de danos ocasionados pelo ácaro rajado o que pode influenciar na atratividade (KRIPS et al., 2001). Sendo assim, o maior número de T. urticae na variedade PS poderia ser atribuído aos voláteis emitidos por ela, os quais podem estar exercendo maior atratividade nesta do que as demais cultivares. Outra possibilidade a ser considerada seria a atratividade natural da variedade PS que, ao liberar voláteis para comunicação interespecífica pode se tornar preferencial ao ácaro rajado (PALLINI et al., 2001). Além deste, outros aspectos, como a coloração das flores, forma das folhas, densidade de tricomas, características bioquímicas e grau de resistência à $\boldsymbol{T}$. urticae também podem ter efeito sobre a abundância dos ácaros em cada cultivar (KIELKIEWICZ \&
DICKE, 1992, SÜTERLIN \& VAN LENEREN, 1997, KRIPS et al., 1999, STAVRINIDES \& SKIRVIN, 2003, WATANABE, 2007).

No que diz respeito à influência de tricomas foliares sobre o ácaro-rajado, estudos (ARAGÃO et al., 2002, GONÇALVES et al., 2006, MATOS et al., 2009) apontam que a presença de tricomas foliares em grande quantidade, pode atuar como fator de repelência à presença e restrição à mobilidade de tetraniquídeos e tarsonemídeos em diferentes cultivares de tomateiro e pimenteira. Neste estudo não foi estabelecida a densidade de tricomas foliares presentes em cada uma das cultivares de gérberas amostradas, não sendo possível avaliar sua influência sobre a popualção de T. urticae. Entretanto, KRIPS et al. (1999) em estudo com gérberas, afirmam que a densidade de tricomas afeta principalmente os inimigos naturais de $\boldsymbol{T}$. urticae, que são em geral, ácaros predadores da família Phytoseiidae que, por serem mais ativos do que os ácaros fitófagos, têm a sua mobilidade mais fortemente restringida pela presença de tricomas. Todavia, neste estudo, apenas um indivíduo pertencente à Phytoseiidae foi registrado ao longo das amostragens, não sendo constatada interação tritrófica neste agroecossistema. Com base nos resultados obtidos, considera-se necessária a continuidade de estudos sobre as relações tritróficas entre T. urticae, ácaros predadores, a densidade de tricomas e voláteis liberados pelas diferentes cultivares de $\boldsymbol{G}$. jamesonii. 
Quanto à preferência do ácaro-rajado por diferentes regiões da planta, a maior quantidade de T. urticae foi registrada nas folhas (6.123 indivíduos; $58,5 \%) \quad(\mathrm{t}=9.106,00 ; \mathrm{P}=0,006)$. A diferença no número de ácaros entre folhas e flores também foi significativa na análise independente para cada uma das variedades (Mann-Whitney): $\mathrm{t}=8.970,00$, $\mathrm{P}=0,016$ (ES); $\mathrm{t}=9.435,50, \mathrm{P}=<0,001(\mathrm{~S}) ; \mathrm{t}=5.476,00$, $\mathrm{P}=0,033$ (PS). A análise das diferenças entre o número de ácaros presentes nas duas regiões amostradas de cada cultivar (flores e folhas) é apresentada na tabela 2. Considerando as variedades e as ocasiões amostrais, em apenas 33,3\% das análises registraramse diferenças significativas, o que não permite uma resposta conclusiva em relação à maior presença dos ácaros em uma das regiões. Todavia, a preferência de tetraniquídeos por diferentes regiões do hospedeiro foi registrada no que diz respeito à idade das folhas por KRIPS et al. (1998) os quais constataram o tempo de desenvolvimento de ovo a ovo mais curto e o pico de oviposição mais alto nas folhas novas da cultivar "Sirtake" em detrimento das folhas maduras e não constaram diferenças significativas ente folhas novas e maduras para estes dois fatores na cultivar "Bianca". Estes autores discutiram a preferência do ácaro-rajado pelas folhas novas devido à diferença de nutrientes presentes em folhas de diferentes idades, como constatado por KIELKIEWICZ \& VAN DE VRIE (1990) que encontraram baixas densidades do ácaro-rajado nas folhas jovens em comparação a folhas maduras de crisântemo (Dendranthrema grandiflora Tzvelev) atribuindo este resultado à alta concentração de mono e polifenóis nas folhas jovens.

O número médio de $\boldsymbol{T}$. urticae presente em folhas e flores em cada uma das três cultivares de gérberas ao longo das amostragens está representado na figura 1 . Todas as cultivares apresentaram maior número médio do ácaro-rajado nos meses de outubro e novembro. Este resultado difere da sazonalidade apresentada por $\boldsymbol{T}$. urticae em outras ornamentais em ambiente protegido. No caso de algumas asteráceas como a dália (Dahlia sp.), a margarida (Leucanthemum vulgare Lam.) e o tagetes (Tagetes erecta L.) o ácaro-rajado apresentou as maiores populações durante o verão, período no qual são, em geral, registrados os ótimos de temperatura e umidade relativa do ar relacionados ao curto ciclo de vida destes ácaros (DEMIRÖZER et al., 2011, HAQUE et al., 2011). Segundo JEPPSON et al. (1975), os ótimos de temperatura para o rápido desenvolvimento de $\boldsymbol{T}$. urticae oscilam entre 25 e $27^{\circ} \mathrm{C}$. No presente estudo temperaturas dentro deste gradiente foram registradas nas amostragens de janeiro e fevereiro; desta forma é possível que o número de $\boldsymbol{T}$. urticae registrado neste período (verão), 32\% menor em relação à primavera, possa ser atribuído à utilização da técnica de controle com ducha de água. Essa ação remove os ácaros presentes em folhas e flores influenciando diretamente a abundância registrada. A diminuição do número de T. urticae pela utilização da ducha de água também foi constado por DEMIRÖZER et al. (2011) em roseiras, na Turquia.

A distribuição do ácaro-rajado entre as cultivares ao longo dos meses apresentou padrão semelhante, sem diferença significativa entre $\mathrm{S}$ e E, com PS apresentando maior número médio; com exceção de novembro, quando não houve diferença significativa entre as três variedades (ANOVA, $\mathrm{h}=4,478 ; \mathrm{P}=0,107$ ) e fevereiro, em que PS e S não apresentaram diferença significativa, com a menor quantidade sendo registrada em $\mathrm{E}(\mathrm{h}=16,812 ; \mathrm{P}<0,01)$. O menor número médio de T. urticae registrado no inverno (julho e setembro)

Tabela 2 - Número médio de Tetranychus urticae por região da planta em três cultivares de Gerbera jamesonii, no período de abril de 2011 a fevereiro de 2012, no município de Dois Irmãos, RS, Brasil.

\begin{tabular}{|c|c|c|c|c|c|c|}
\hline \multirow{2}{*}{ Data } & \multirow[b]{2}{*}{ Flor } & \multirow[b]{2}{*}{ Folha } & \multirow[b]{2}{*}{ Flor } & \multirow[b]{2}{*}{ Folha } & \multirow[b]{2}{*}{ Flor } & \multirow[b]{2}{*}{ Folha } \\
\hline & & & & & & \\
\hline Abril/2011 & $13,9 a$ & $7,6 a$ & $38,6 a$ & $37,1 \mathrm{a}$ & $10,7 \mathrm{a}$ & $11,8 \mathrm{a}$ \\
\hline Junho/2011 & $2,7 \mathrm{a}$ & $8,9 b$ & $45,2 \mathrm{a}$ & $50,4 \mathrm{a}$ & $0,5 \mathrm{a}$ & $11,7 \mathrm{~b}$ \\
\hline Julho/2011 & $0,2 \mathrm{a}$ & $1,9 \mathrm{a}$ & $11,3 \mathrm{a}$ & $23,7 \mathrm{a}$ & $0,4 \mathrm{a}$ & $3,3 a$ \\
\hline Setembro/2011 & $0,1 \mathrm{a}$ & $0,8 b$ & $9,4 \mathrm{a}$ & $26,1 \mathrm{a}$ & $0,8 \mathrm{a}$ & $1,7 \mathrm{~b}$ \\
\hline Outubro/2011 & $32,0 \mathrm{a}$ & $16,4 \mathrm{a}$ & $90,0 \mathrm{a}$ & $66,6 \mathrm{a}$ & $22,4 \mathrm{a}$ & $27,8 \mathrm{a}$ \\
\hline Novembro/2011 & $33,4 \mathrm{a}$ & $52,3 \mathrm{a}$ & $49,8 \mathrm{a}$ & $70,9 a$ & $27,7 \mathrm{a}$ & $68,5 b$ \\
\hline Janeiro/2012 & $14,0 \mathrm{a}$ & $14,5 \mathrm{~b}$ & $29,0 \mathrm{a}$ & $47,0 \mathrm{~b}$ & $2,7 \mathrm{a}$ & $15,4 \mathrm{a}$ \\
\hline Fevereiro/2012 & $0 \mathrm{a}$ & $15,1 b$ & $5,8 \mathrm{a}$ & $20,1 \mathrm{a}$ & $11,1 \mathrm{a}$ & $12,7 \mathrm{~b}$ \\
\hline
\end{tabular}

Valores nas linhas para cada variedade, seguidos por letras iguais não diferem estatisticamente de acordo com o Teste $\mathrm{t}$ de $\mathrm{Student}$ ( $\mathrm{P}<0,05) \mathrm{e}$ Mann-Whitney $(\mathrm{P}<0,05)$. 


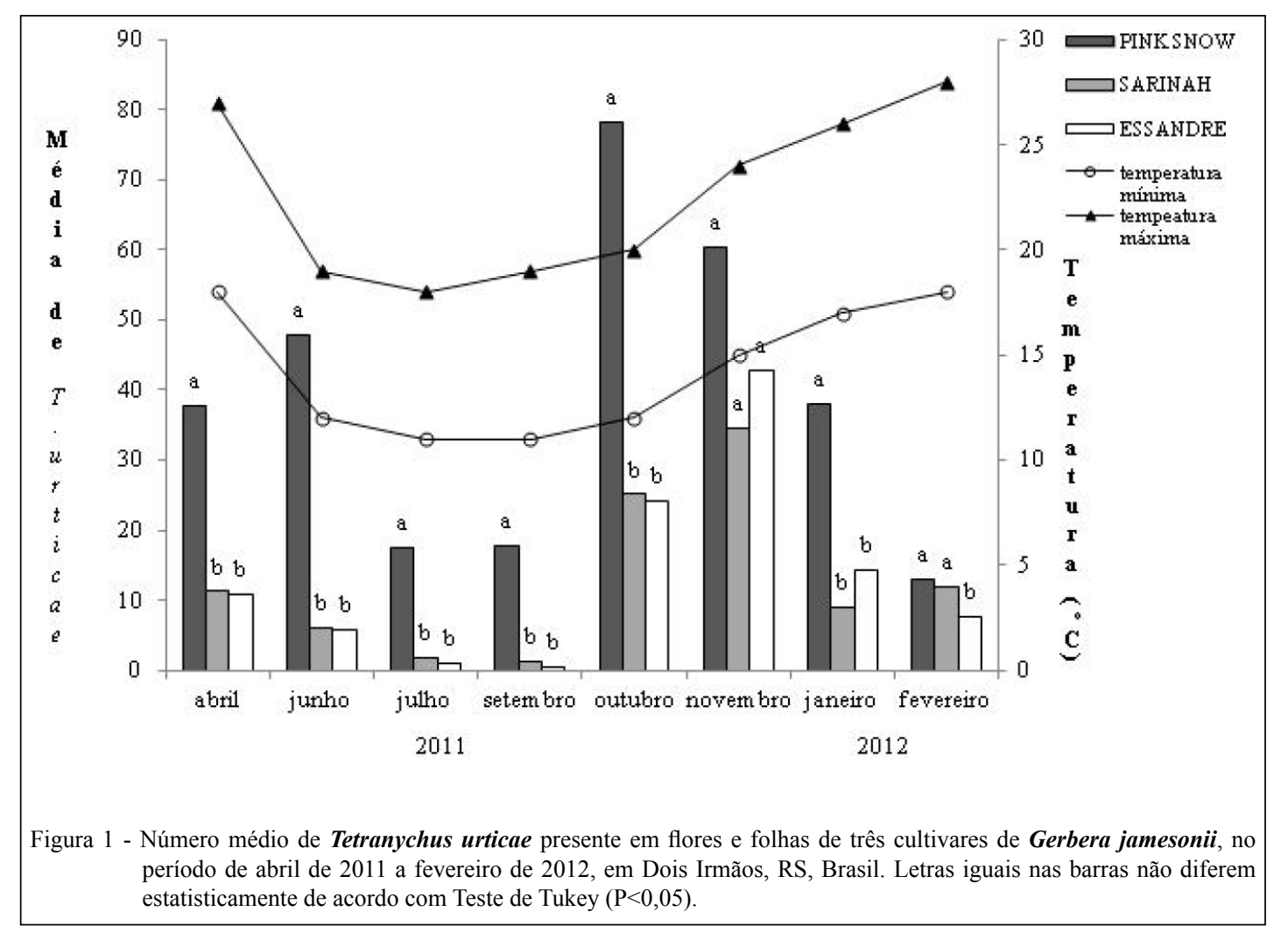

nas cultivares E e S, pode ser considerado esperado, pois neste período as populações de ácaros tendem a diminuir sua taxa reprodutiva em razão das baixas temperaturas. Este resultado é corroborado pelos estudos de DEMIRÖZER et al. (2011) e HAQUE et al. (2011) que registraram as menores densidades de T. urticae no inverno. Todavia, a cultivar PS que apresentou o maior número médio do ácaro-rajado em todas as amostragens, registrou a menor média em fevereiro (verão), possivelmente em razão do controle realizado com a ducha de água.

O tratamento fitossanitário utilizado pelo produtor, no que diz respeito ao controle químico, foi o mesmo durante todo o período de amostragens. É possível que o controle químico preventivo de T. urticae, principalmente no que diz respeito aos inseticidas e acaricidas com princípios ativos a base de abamectina e milbemectina combinados com aplicações semanais de fungicidas, possa estar induzindo a população de ácaros à resistência. Esse fato pode ser evidenciado pelo alto número médio registrado nas gérberas (24,3 ácaros/ flor/amostragem e 25,5 ácaros/folha/amostragem). Esse número pode ser considerado alto quando comparado ao número médio de $\boldsymbol{T}$. urticae registrado em folhas de roseiras (2,1 ácaros/folha/amostragem), que apresentavam injúrias ocasionadas por esse ácaro, não tendo sido utilizado nenhum tipo de controle fitossanitário no cultivo (DEMIRÖZER et al., 2011). Apesar do produtor de gérberas em Dois Irmãos, RS utilizar o sistema de rotação de ingredientes ativos para evitar a resistência, de acordo com SATO (2010) em culturas como algodão, mamão, feijão, uva, morango e a ornamental crisântemo, são necessários alguns meses sem a aplicação de abamectina e milbemectina para que se reestabeleça a suscetibilidade de $\boldsymbol{T}$. urticae a estes princípios ativos. $\mathrm{O}$ mesmo autor sugere ainda que a aplicação de acaricidas seja realizada somente quando a população atingir níveis que possam causar prejuízo econômico, pois favoreceria o manejo da resistência devido à menor pressão de seleção com os acaricidas. Dessa forma, o controle químico preventivo de $\boldsymbol{T}$. urticae aplicado pelo produtor no cultivo de gérberas com aplicações semanais, provavelmente possa estar promovendo o desenvolvimento da resistência dos ácaros. Além disso o uso de produtos não seletivos aos inimigos naturais não permite o estabelecimento de predadores, o que pode ser evidenciado através do registro de apenas um fitoseídeo durante o período de amostragens.

Uma técnica para evitar a resistência de $\boldsymbol{T}$. urticae e alternativa à lavagem com ducha em grande escala, que pode se tornar inviável, seria a utilização 
do controle biológico aplicado com a liberação massal de ácaros predadores das espécies Neoseiulus californicus (MacGregor) e Phytoseiulus macropilis (Banks) as quais estão disponíveis no mercado brasileiro e têm-se demonstrado eficientes no controle de ácaros em cultivo protegido.

\section{CONCLUSÃO}

A maior densidade do ácaro-rajado foi registrada na cultivar 'Pink Snow'. As cultivares de $\boldsymbol{G}$. jamesonii não apresentaram diferenças significativas no número de $\boldsymbol{T}$. urticae presentes em folhas e flores. De acordo com a sazonalidade, a maior densidade do ácaro-rajado foi registrada nos meses de primavera (outubro e setembro) nas três variedades. A distribuição sazonal da espécie provavelmente foi influenciada pelas baixas temperaturas no inverno e pelo manejo fitossanitário no verão com a utilização da ducha de água para o controle de T. urticae.

\section{AGRADECIMENTOS}

À Floricultura Florist, na pessoa do Sr. Yuuki Ban pelo apoio e incentivo à pesquisa científica. À Fundação de Amparo à Pesquisa do Estado do Rio Grande do Su (FAPERGS), ao Programa Institucional de Bolsas de Iniciação Científica (PROBIC) e a Fundação Zoobotânica do Rio Grande do Sul (FZBRS) pela concessão de bolsa de iniciação científica (Processo 11/0418-6) ao primeiro autor.

\section{REFERÊNCIAS}

ARAGÃO, C.A. et al. Efeito de aleloquímicos em tricomas foliares de tomateiro na repelência ao ácaro (Tetranychus urticae Koch) em genótipos com teores contrastantes de 2-Tridecanona. Acta Botânica Brasileira, v.16, n.1, p.83-88, 2002. Disponível em: $<$ http://www.scielo.br.php?script=sci_arttex t\&pid=S0102-33062002000100010>. Acesso em: 22 out 2013.doi: $10.1590 / \mathrm{S} 0102-33062002000100010$.

BAKER, E.W., TUTLLE, D.M. 1994. A guide to the spider mites (Tetranychidae) of the United States. West Bloomfield: Indira Publishing House, 1994. 347p.

BUAINAIN, A.M.; BATALHA, M.O. Cadeia produtiva de flores e mel. Brasília: IICA: MAPA/SPA, 2007. 140p.

DEMIRÖZER, O. et al. Population fluctuations of some important pests and natural enemies find in Oil-bearing rose (Rosa damascena Miller) production areas in Isparta province (Turkey). Türkish Entomology Dergisi, v. 35, n.4, p.539-558, 2011. Disponível em: <http://www. entomoloji.ege.edu.tr/files/arsiv/2011_35_4/2011_35_4_539-558. pdf $>$. Acesso em: 22 out 2013.

DICKE, M. Infochemicals in tritrophic interactions. Origin and function in a system consisting of predatory mites, phytophagous mites and their host plants. 1998a. 235f. Tese (Doutorado em Agricultura) - Agricultural University, Wageningen.
DICKE, M. Prey preference of the phytoseiid mite Typhlodromus pyri: Response to volatile kairomones. Experimental and Applied Acarology, v.4, n.1, p.1-13, 1988b. Disponível em: <http://link. springer.com/article/10.1007/BF01213837\#page-1>. Acesso em: 21 out. 2013. doi: 10.1007/BF01213837.

ESTEVES FILHO, A.B. et al. Biologia comparada e comportamento de Tetranychus urticae Koch (Acari: Tetranyhcidae) e Phytoseiulus macropilis (Banks) (Acari: Phytoseiidae) em algodoeiro Bollgard e Isolinha não-transgênica. Neotropical Entomology, v.39, n.3, p.338-344, 2010. Disponível em: <http:// dx.doi.org/10.1590/S1519-566X2010000300005>. Acesso em: 21 out. 2013. doi: 10.1590/ S1519-566X2010000300005.

FERES, R.J.F. et al. Ácaros (Arachnida, Acari) de plantas ornamentais na região noroeste do estado de São Paulo, Brasil: inventário e descrição dos sintomas causados pelos fitófagos. Revista Brasileira de Entomologia, v.53, n.3, p.466-474, 2009. Disponível em: <http://www.scielo.br/pdf/rbent/v53n3/24.pdf $>$. Acesso em: 21 out. 2013.

FISCHER, S.Z. Gérbera. In: BARBIERI, R.L.; STUMPF, E.R.T (eds). Origem e evolução de plantas cultivadas. Brasília: Embrapa Informação Tecnológica, 2008. 909p.

GALlO, D. et al. Entomologia Agrícola. Piracicaba: FEALQ, 2002. 920p

GONÇALVES, L.D. et al. Relação entre zingibereno, tricomas foliares e repelência de tomateiros a Tetranychus evansi. Pesquisa Agropecuária Brasileira, v.41,n.2, p.267-273, 2006.

HAQUE, M. et al. Seasonal abundance of spider mite Tetranychus urticae Koch on vegetable and ornamental plants in Rajshahi. University Journal of Zoology of Rajsahi University, v.30, p.3740, 2011. Disponível em: <http://www.banglajol.info/index.php/ UJZRU/article.view/10745/7897>. Acesso em: 22 out 2013. doi: http://dx.doi.org/10.3329/ujzru.v30i0.10745.

JANDEL, C. 2007. SigmaStat. San Jose: Jandel Corporation, 2007. V.3.5.

JEPPSON, L. et al. Mites injurious to economic plants. Berkeley: University of California, 1975. 614p.

KIELKIEWICZ, M., DICKE, M. Effects of spider mite infestation on biochemical characteristics of different gerbera cultivars. Proceedings of the $8^{\text {th }}$ International Symposium on Insect-Plant Relationships. In: MENKEN, J.H. et al. (Eds). Dordrecht: Kluwer Acad. Publ. , 1992. p.311-312.

KIELKIEWICZ, M., Van DE VRIE, M. Within-leaf differences in nutritive value and defence mechanism in chrysanthemum to the two-spotted spider mite (Tetranychus urticae). Experimental and Applied Acarology, v.10, n.1, p.33-43, 1990. Disponível em: <http://dowload.springer.com/static/ pdf/957/art\%253A10.1007\%FBF01193971.pdf>. Acesso em: 29 set 2014 .

KRIPS, O.E. et al. Intrinsic rate of population increase of the spider mite Tetranychus urticae on the ornamental crop gerbera: Intraspecific variation in host plant and herbivore. Entomologia Experimentalis et Applicata, v.89, n.2, p.159168, 1998. Disponível em: <http://www.onlinelibrary.wiley.com/ doi/10.1046/j. 1570-7458.1998.00.395.x /abstract>. Acesso em: 21 out 2013. doi: 10.1046/j.1570-7458.1998.00.395.x. 
KRIPS, O.E. et al. Leaf hairs influence searching efficiency and predation rate of the predatory mite Phytoseiulus persimilis (Acari: Phytoseiidae). Experimental and Applied Acarology, v.23, n.2, p.119-131, 1999. Disponível em: <http://www.link.springer.com/ article/10.1023/A\%3A1006098410165>. Acesso em: 21 out 2013. doi:10.1023/A:1006098410165.

KRIPS, O.E. et al.. Comparison of cultivars of ornamental crop Gerbera jamesonii on production of spider mite-induced volatiles, and their attractiveness to the predator Phytoseiulus persimilis. Journal of Chemical Ecology, v.27, n.7, p.1355-1372, 2001 Disponível em: <http://dowload.springer.com/static/pdf/476/art\% 253A10.1023\%53A1010313209110.pdf?auth66 $=14121854236 \mathrm{~b}$ 6dac1d35509a9f016531ebf8c6a0da\&ext.pdf>. Acesso em: 29 set 2014.

LOURENÇÃO, A.L. et al. Resistência de morangueiros a Tetranychus urticae Koch (Acari: Tetranychidae). Anais da Sociedade Entomológica do Brasil, v.29, n.2, p.339-346, 2000. Disponível em: <http://dx.doi.org/10.1590/S030185592000000300023>. Acesso em: 29 set 2014. doi: 10.1590/ S0301-85592000000300023.

MARUYAMA, W.I. et al. Resistência de genótipos de tomateiro ao ácaro rajado. Horticultura Brasileira, v.20, n.3, p.480-484, 2002. Disponível em: <http://www.scielo.br/pdf/hb/v20n3/14474.pdf $>$. Acesso em: 12 fev. 2014

MATOS, C.H.C. et al. Os tricomas de Capsicum spp. interferem nos aspectos biológicos do ácaro-branco Polyphagotarsonemus latus Banks (Acari: Tarsonemidae)? Neotropical Entomology, v. 38, n.5, p.589-594, 2009. Disponível em: <http://www.scielo.br/ pdf/ne/v38n5a05.pdf>. Acesso em: 29 set. 2014

MORO, L. B. et al. Parâmetros biológicos e tabela de vida de Tetranychus urticae (Acari: Tetranychidae) em cultivares de mamão. Ciência Rural, v.42, n.3, p.487-493, 2012. Disponível em:<http://dx.doi.org/10.1590/S0103-84782012000300016>. Acesso em: 29 set. 2014. doi: 10.1590/S0103-84782012000300016.

PALLINI, A. et al. Odour-mediated responses of phytophagous mites to conspecific and heterospecific competitors. Oecologia, v.110, p.179-185, 1997. Disponível em: <http://link.springer.com/ article/10.1007/s004420050147>. Acesso em: 21 out 2013. doi: $10.1007 / \mathrm{s} 004420050147$.

PALLINI, A. et al. Infoquímicos de ácaros mediando interações em teias alimentares. In: VILELA, E.F.; DELLA LUCIA, T.M.C. (Eds). Feromônios de insetos. Biologia, química e aplicação. Ribeirão Preto: Holos, 2001. p.113-120.

SANTOS, R.M.V. et al. Ácaros (Arachnida: Acari) associados a plantas ornamentais tropicais na região litoral sul da Bahia. Arquivo Instituto Biológico, v.77, n.1, p. 43-48, 2010. Disponível em: <http://www.biologico.sp.gov.br/docs/arq/v77 1/santos.pdf>. Acesso em: 21 out 2013.

SATO, M.E. Manejo da resistência do ácaro rajado em culturas. IRAC- BR, Folder. 2010. Disponível em: <http://www.irac-br.org. br/Arquivos/Folder>. Acesso em: 21 fev. 2014.
SCHWERTNER, C. Controle do Ácaro rajado (Tetranychus urticae Koch) na cultura de gérberas (Gerbera jamesonii Adlam) em estufa. 2012. 76f. Dissertação (Mestrado em Ambiente e Desenvolvimento), UNIVATES, Lajeado, RS

SEBRAE. Diagnóstico da cadeia produtiva de flores e plantas ornamentais do Rio Grande do Sul. Porto Alegre: Vangraf, 2003. 159 p.

SEBRAE. Mercado de flores e plantas movimenta R\$ 3,8 bilhões no país. Disponível em: <http://www.agenciaseabre.com br/noticia.kmf?canal $=199 \& \operatorname{cod}=10808941>$. Acesso em: 21 out 2013.

SENAPATI, A.K. et al. Genetic variability and heritability studies on Gerbera jamesonii Bolus. African Journal of Agricultural Research, v.8, n.41, p.5090-5092, 2013. Disponível em: $<$ http://www.academicjournals.org/article/article 1382093353 Senapati\%20et\%20al.pdf>. Acesso em: 29 set 2014. doi: 10.5897/ AJAR2013.8038

SILVA, E.A. et al.. Tetranychus urticae (Acari: Tetranychidae) on Gerbera jamesonii Bolus and Hook (Asteraceae). Brazilian Journal Biology, v.69, n.4, p.1121-1125, 2009. Disponível em: $<$ http://www.scielo.br/pdf/bjb/v69n4/v69n4a16.pdf $>$. Acesso em: 21 out 2013. doi: 10.1590/S1519-69842009000500016.

STAVRINIDES, M.C., SKIRVIN, D.J. The effect of chrysanthemum leaf trichome density and prey spatial distribution on predation of Tetranychus urticae (Acari: Tetranychidae) by Phytoseiulus persimilis (Acari: Phytoseiidae). Bulletin of Entomological Research, v.93, n.4, p.343-350, 2003. Disponível em: <http://journals.cambridge.org/dowload.php?file=\%2FBER $\%$ 2FBER93_04\%FSF000748533000415a.pdf\&code=b76900bbb14 4d785ae713db408d36660>. Acesso em: 29 set 2014. doi: 10.1079/ BER2003243.

SÜTERLIN, S., VAN LETEREN, J.C. Influence of hairiness of Gerbera jamesonii leaves on the searching efficiency of the parasitoid Encarsia formosa. Biological Control, v.9, p.157165,1997. Disponível em: <http:/www.sciencedirect.com/science/ article/pii/S1049964497905302\#>. Acesso em: 21 out 2013.

TAKABAYASHI, J. et al. Variation in composition of predatorattracting allelochemicals emitted by herbivore-infested plants: relative influence of plant and herbivore. Chemoecology, v.2, p.16, 1991. Disponível em: <http://link.springer.com/journal/49/2/1/ page/1>. Acesso em: 21 out 2013. doi:10.1007/BF01240659.

VILELA, E. F. Ácaros Tetranychoidea (Acari) do município de Viçosa, Estado de Minas Gerais. 1975. 39f. Dissertação (Mestrado em Agronomia) - Escola Superior de Agricultura "Luiz de Queiroz” da Universidade de São Paulo, Piracicaba, SP.

ZHANG, Z. Mites of greenhouses: identification, biology and control. Cambridge: CABI Publishing, 2003. 244p.

WATANABE, M.A. Fatores que influenciam a ocorrência de ácaros em flores de Lantana camara L. Jaguariúna: Embrapa Meio Ambiente, 2007. 24p. 